\title{
Halogen Bonding in a Crystalline Sponge
}

\author{
Liangqian Yuan, ${ }^{\mathrm{a}}$ Siyu Li, ${ }^{\mathrm{a}}$ and Fangfang Pan ${ }^{\mathrm{a} *}$ \\ a Central China Normal University, Key Laboratory of Pesticide \& Chemical Biology of Ministry of \\ Education, Hubei International Scientific and Technological Cooperation Base of Pesticide and Green \\ Synthesis, College of Chemistry
}

Supporting Information 


\section{GENERAL INFORMATION}

The crystalline sponge CS-1 was synthesized according to reported procedures. ${ }^{1}$ All the other chemicals were commercially available and used without further treatment. Infrared spectra were measured on an Avatar Nicolet 360 spectrometer. Melting points were determined with a Mettler Toledo FP62 capillary melting point apparatus. TGA was carried out on a Perkin-Elmer TGA instrument. The experiments were performed from ambient temperature (ca. $30{ }^{\circ} \mathrm{C}$ ) to $800{ }^{\circ} \mathrm{C}$ with the heating rate of $5{ }^{\circ} \mathrm{C} / \mathrm{min}$.

\section{SYNTHESIS}

Synthetic details of CSF-1, DITFB@MST@CSF-1, and DIB@Dox@CSF-1.

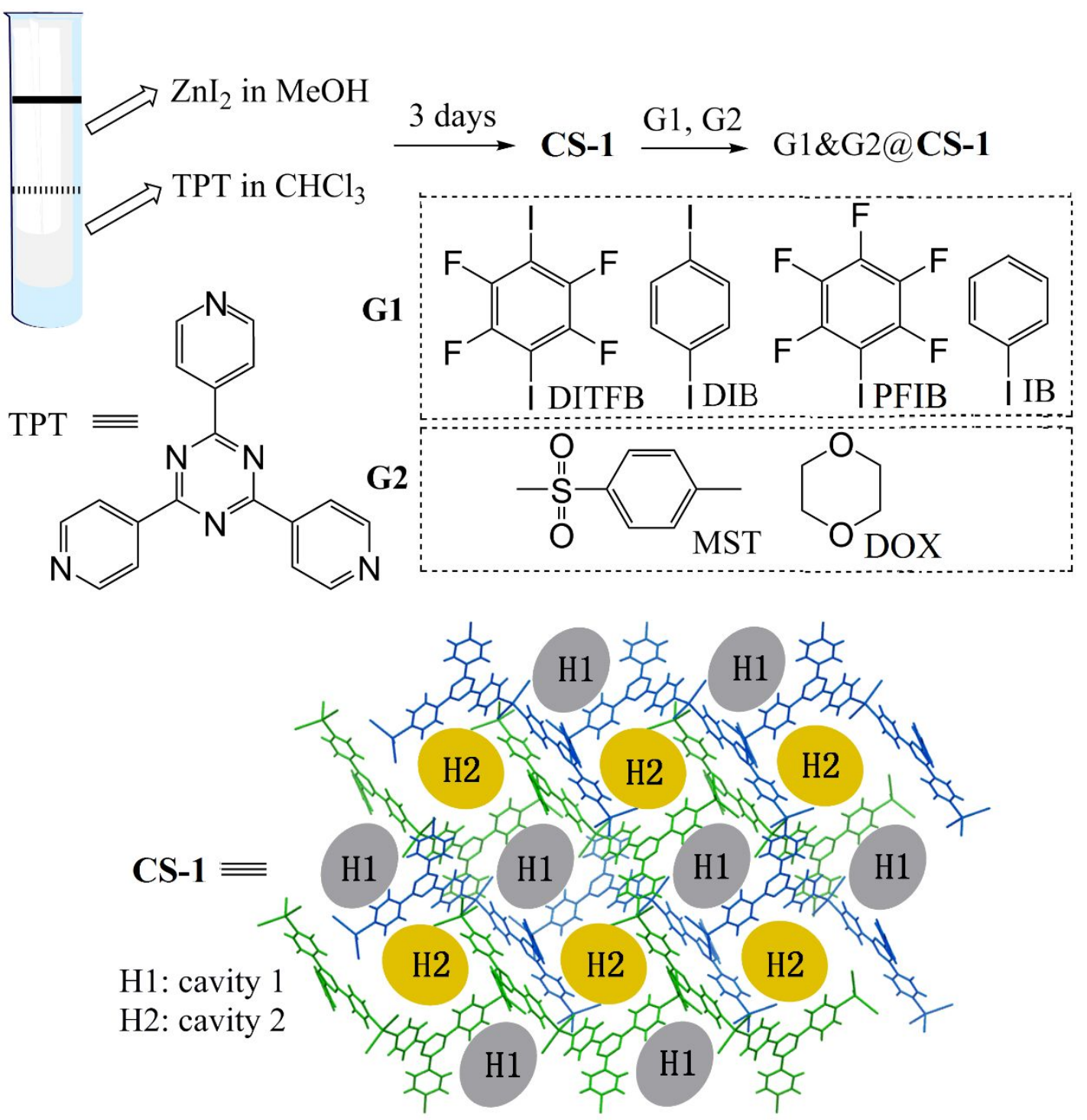

Figure S1. Synthesis of CS-1, and G1\&G2@CS-1. 
CS-1: $6.3 \mathrm{mg}$ (0.020 mmol) tris(4-pyridyl)-1,3,5-triazine was dissolved in ca. $4 \mathrm{ml}$ $\mathrm{CHCl} 3$ by sonication. The solution was added to a $12 \times 75 \mathrm{~mm}$ test tube. On top of this solution was layered carefully with $1 \mathrm{ml} \mathrm{MeOH}$ solution containing $9.6 \mathrm{mg} \mathrm{ZnI}_{2}(0.03$ mmol). The test tube was sealed and kept undisturbed at ambient conditions for three days. Colorless plate crystals were obtained on the wall of the test tube with the yield of ca. $60 \%$. The crystals were carefully token from the test tube and washed with pure $\mathrm{CHCl}_{3}$ to wash away the impurity (m.p. $342^{\circ} \mathrm{C}$ ).

DITFB\&MST@CS-1: Dissolve ca. 100.5 mg (0.25 mmol) DITFB and 85.0 mg (0.50 $\mathrm{mmol}$ ) MST in ca. $1 \mathrm{ml} \mathrm{CHCl}_{3}$. The solution was filtered with microfiber (pore size 0.2 $\mu \mathrm{m})$. Immerse several crystals of CS-1 to the DITFB/MST/CHCl 3 pure solution. After three days, IR was measured to check the absorption of the guest molecules. Before IR measurement, the crystals were wash with pure $\mathrm{CHCl}_{3}$ solvent $(4 * 10 \mathrm{ml})$.

DIB\&DOX@CS-1: Dissolve 82.5 mg (mmol) DIB in ca. $1 \mathrm{ml} \mathrm{1,4-dioxane.} \mathrm{The}$ solution was filtered with microfiber (pore size $0.2 \mu \mathrm{m}$ ). Immerse several crystals of CS-1 to the DIB/DOX solution. After three days, IR was measured to check the absorption of the guest molecules. Before IR measurement, the crystals were wash with pure $\mathrm{CHCl}_{3}$ solvent $(4 * 10 \mathrm{ml})$.

IB\&MST@CS-1: Dissolve ca. $85.11 \mathrm{mg}(0.50 \mathrm{mmol})$ MST in ca. $1 \mathrm{ml}(8.92 \mathrm{mmol})$ IB. The solution was filtered with microfiber (pore size $0.2 \mu \mathrm{m}$ ). Immerse several crystals of CS-1 to the IB/MST pure solution. After three days, IR was measured to check the absorption of the guest molecules. Before IR measurement, the crystals were washed with pure $\mathrm{CHCl}_{3}$ solvent $(4 * 10 \mathrm{ml})$.

PFIB\&MST@CS-1: Dissolve ca. $85.11 \mathrm{mg}(0.50 \mathrm{mmol})$ MST in $1 \mathrm{ml} \mathrm{CHCl} 3$, then use a micro-injector to add $66.69 \mu \mathrm{l}(0.50 \mathrm{mmol})$ PFIB to it. The solution was filtered with microfiber (pore size $0.2 \mu \mathrm{m}$ ). Immerse several crystals of CS-1 to the PFIB/MST pure solution. After three days, IR was measured to check the absorption of the guest molecules. Before IR measurement, the crystals were washed with pure $\mathrm{CHCl}_{3}$ solvent $(4 * 10 \mathrm{ml})$.

IB\&DOX@CS-1: Mix ca. $1 \mathrm{ml}(8.92 \mathrm{mmol})$ and $1 \mathrm{ml}$ 1,4-dioxane. The solution was filtered with microfiber (pore size $0.2 \mu \mathrm{m}$ ). Immerse several crystals of CS-1 to the IB/DOX solution. After three days, IR was measured to check the absorption of the guest molecules. Before IR measurement, the crystals were wash with pure $\mathrm{CHCl}_{3}$ solvent $(4 * 10 \mathrm{ml})$.

PFIB\&DOX@CS-1: Inject $66.69 \mu 1(0.50 \mathrm{mmol})$ PFIB with a micro-injector and $1 \mathrm{ml}$ 1,4-dioxane. The solution was filtered with microfiber (pore size $0.2 \mu \mathrm{m}$ ). Immerse several crystals of CS-1 to the PFIB/DOX solution. After three days, IR was measured to check the absorption of the guest molecules. Before IR measurement, the crystals were wash with pure $\mathrm{CHCl}_{3}$ solvent $(4 * 10 \mathrm{ml})$. 


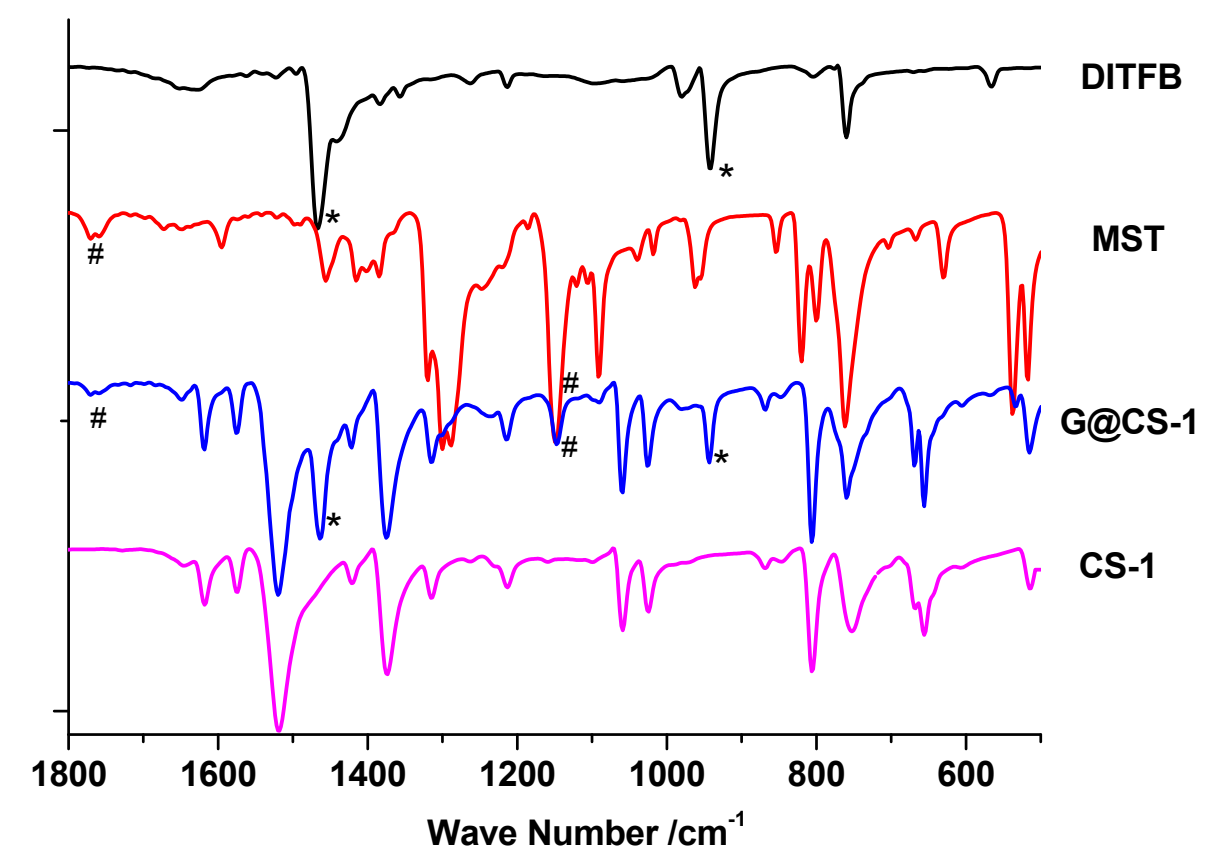

Figure S2. The IR spec. for DITFB, MST, CS-1 and DITFB\&MST@CS-1. The* and \# indicate the existence of DITFB and MST in the G@CS-1, respectively.

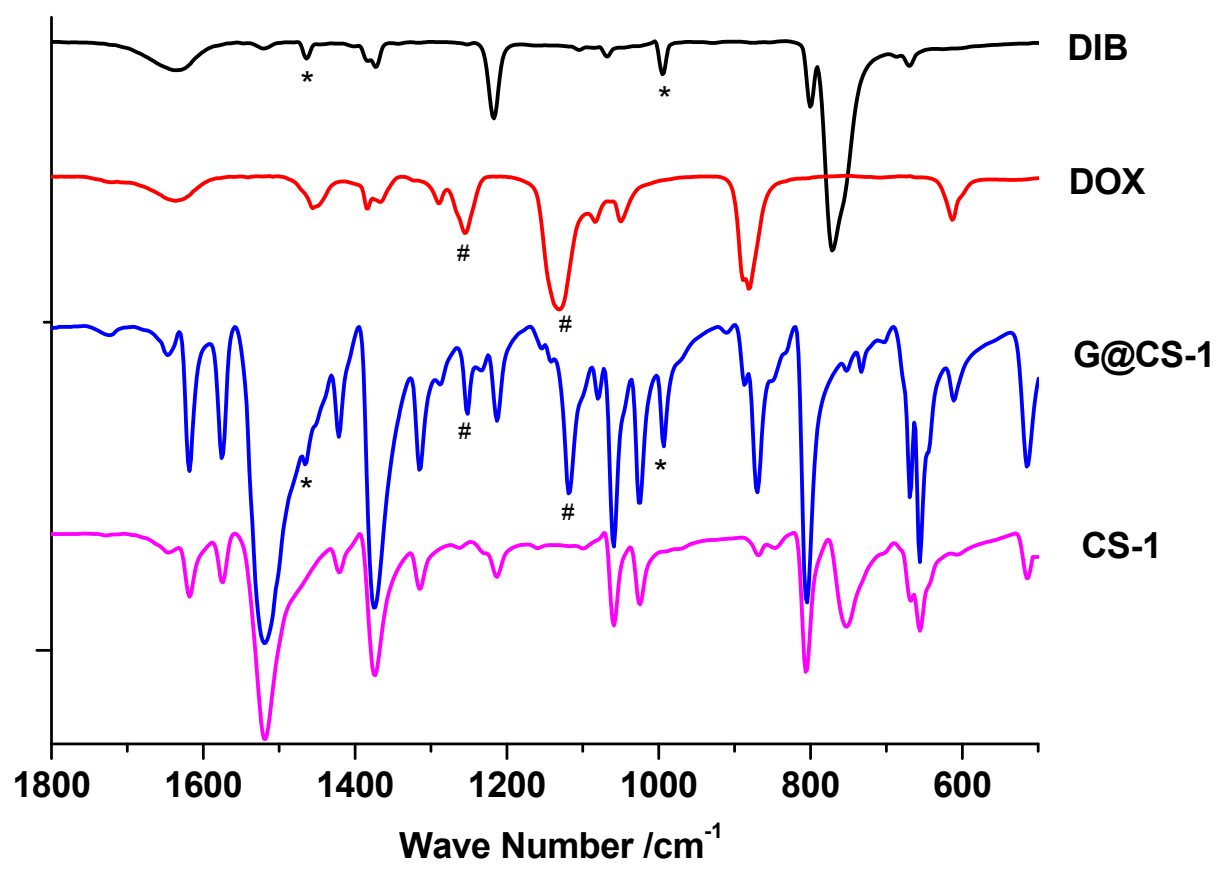

Figure S3. The IR spec. for DIB, DOX, CS-1 and DIB\&DOX@CS-1. The * and \# indicate the existence of DIB and DOX in the G@CS-1, respectively. 


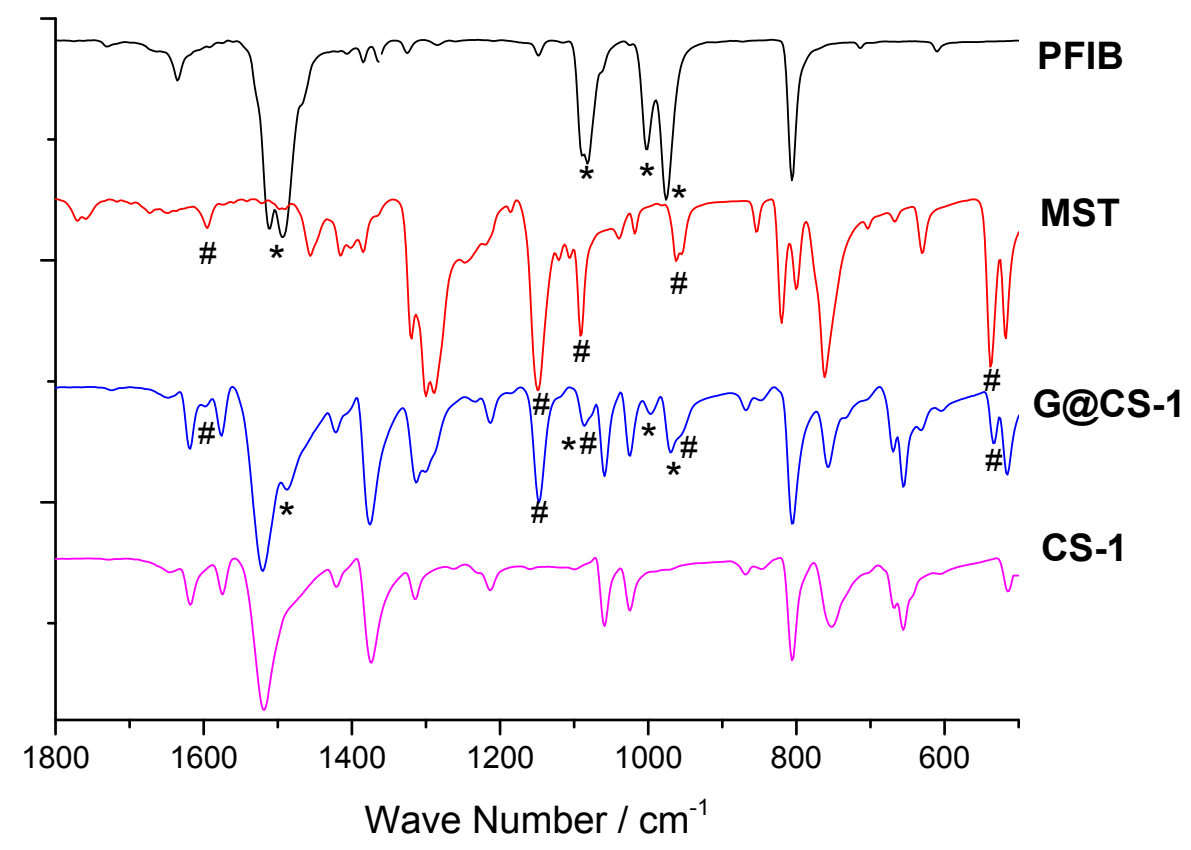

Figure S4. The IR spec. for PFIB, MST, CS-1 and PFIB\&MST@CS-1. The * and \# indicate the existence of PFIB and MST in the G@CS-1, respectively.

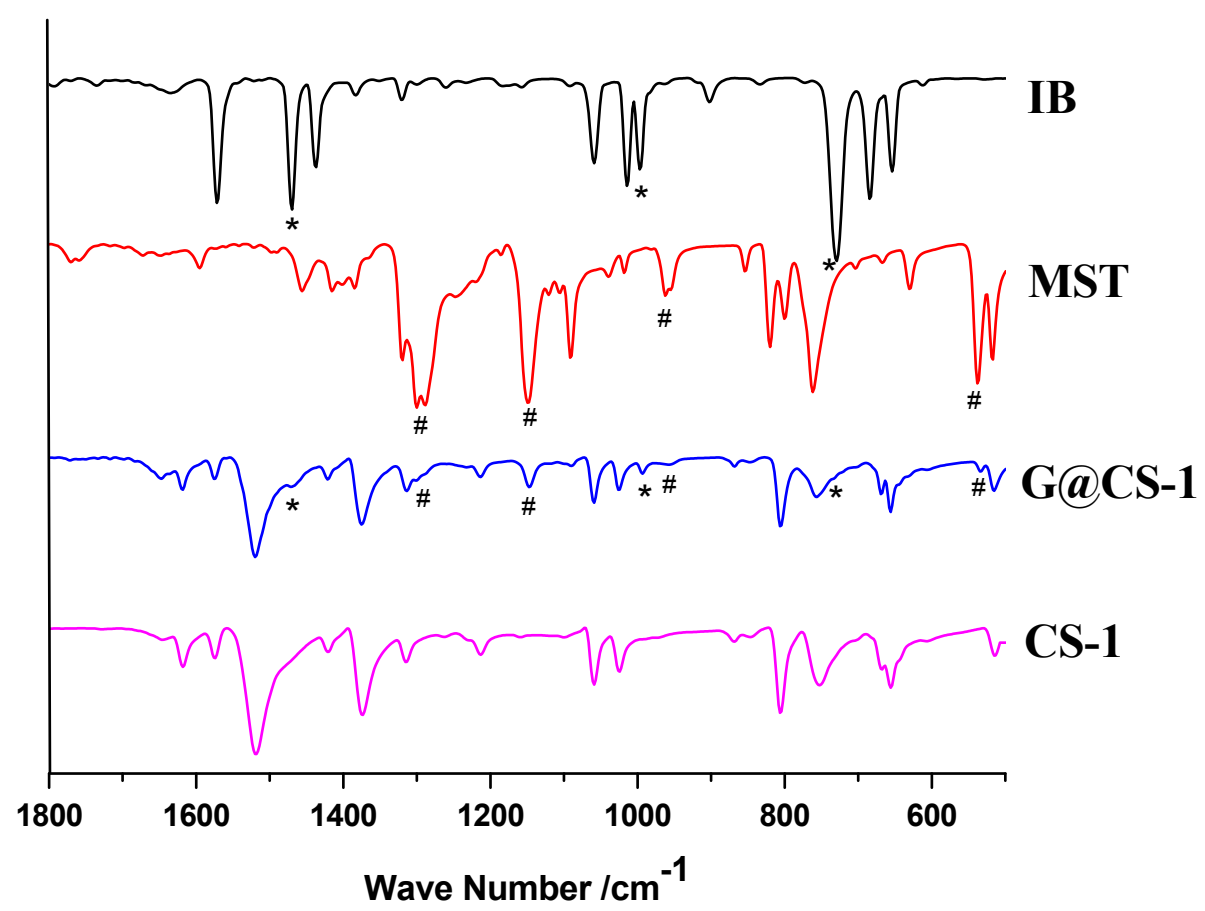

Figure S5. The IR spec. for IB, MST, CS-1 and IB\&MST@CS-1. The * and \# indicate the existence of IB and MST in the G@CS-1, respectively. 


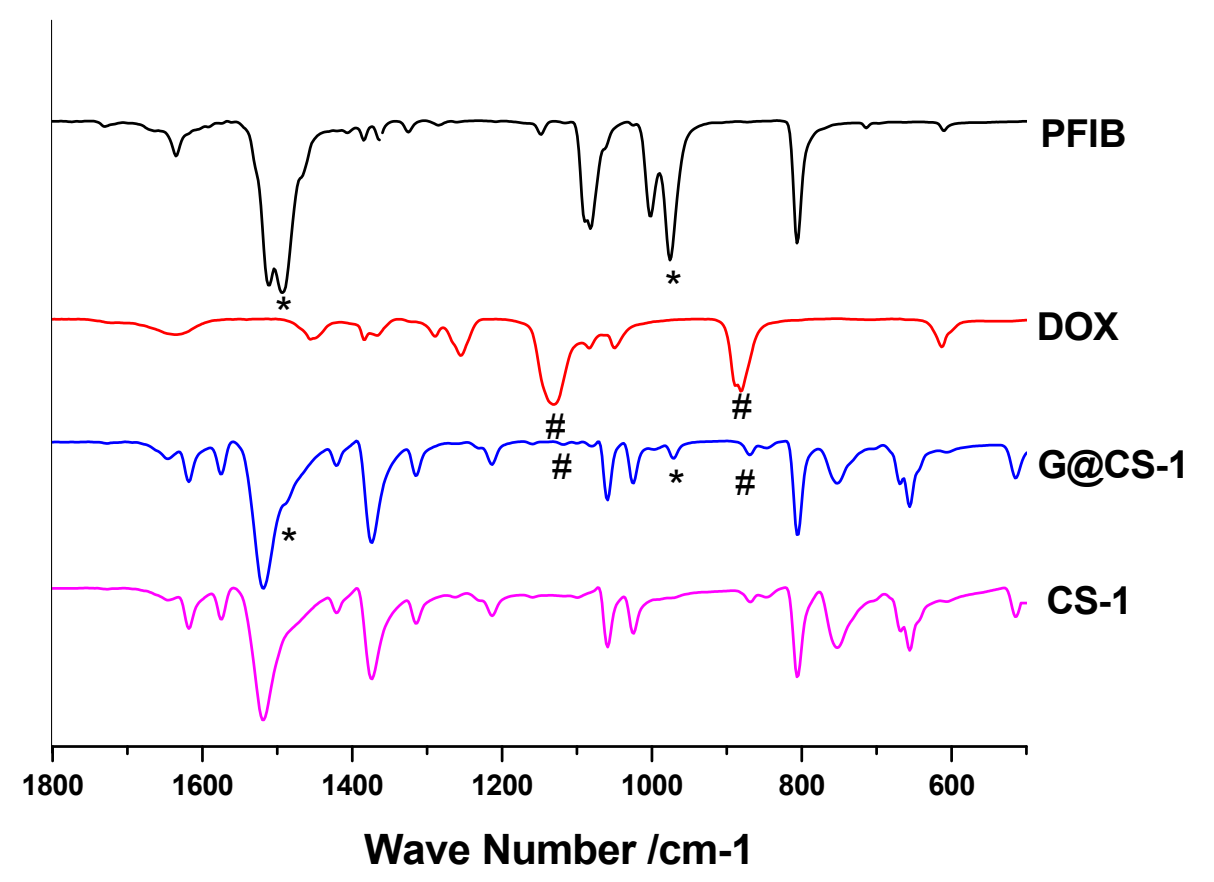

Figure S6. The IR spec. for PFIB, DOX, CS-1 and PFIB\&DOX@CS-1. The * and \# indicate the existence of PFIB and DOX in the G@CS-1, respectively.

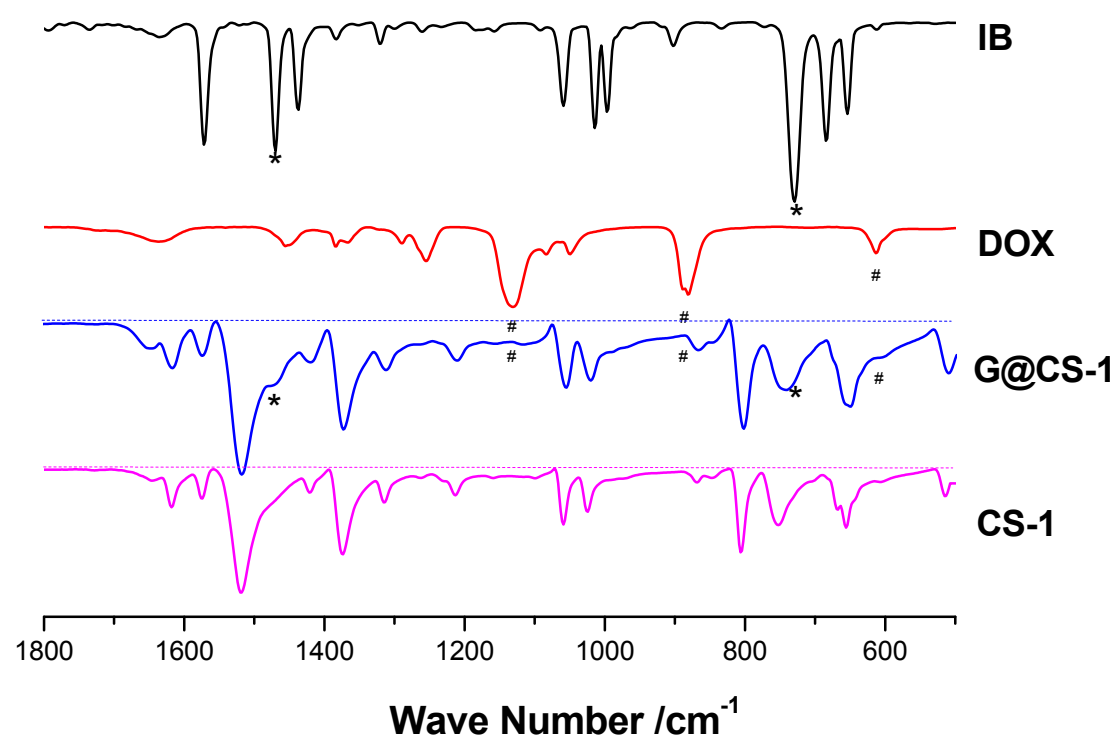

Figure S7. The IR spec. for IB, DOX, CS-1 and IB\&DOX@CS-1. The * and \# indicate the existence of IB and DOX in the G@CS-1, respectively. 
IV TGA of the crystals of G1\&G2@CS-1

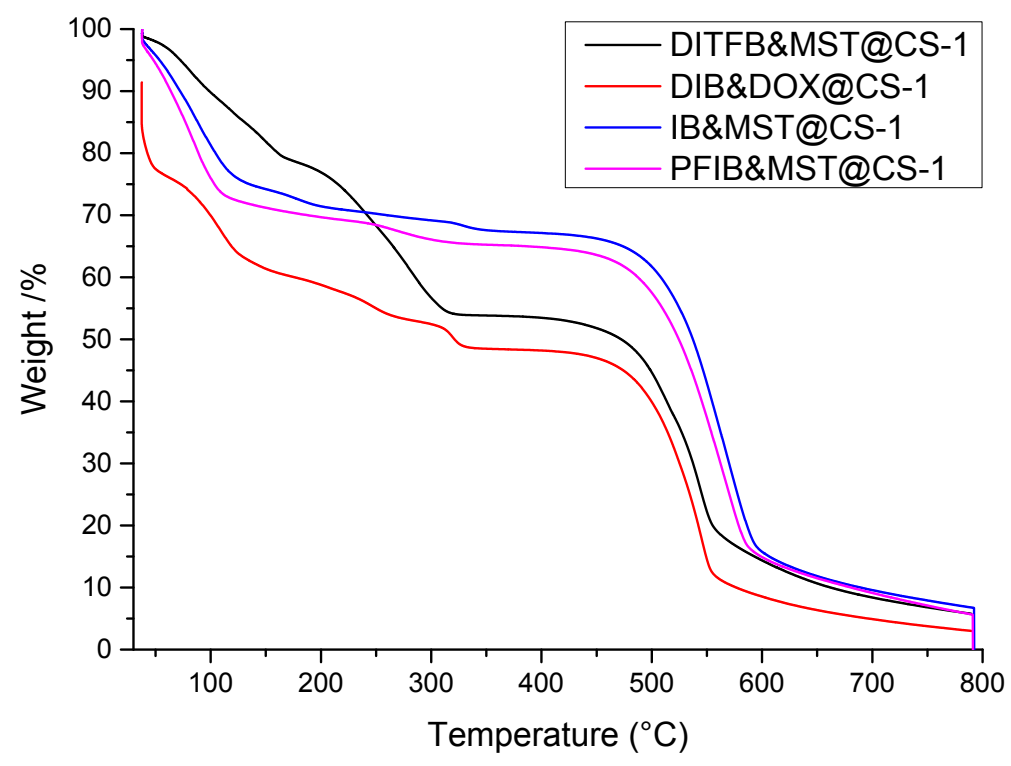

Figure S8. The TGA of DITFB\&MST@CS-1, DIB@DOX@CS-1, IB\&MST@CS-1 and PFIB\&MST@CS-1.

Table S1. Analysis of the TGA results.

\begin{tabular}{|c|c|c|c|c|c|c|c|}
\hline G@CS-1 & Substance & Molecular formula & $\begin{array}{l}\text { Molecular } \\
\text { weight }\end{array}$ & $\begin{array}{l}\text { Ratio } \\
\text { (\%) }\end{array}$ & $\begin{array}{l}\text { Weight } \\
\text { loss (\%) }\end{array}$ & $\mathrm{t}\left({ }^{\circ} \mathrm{C}\right)$ & Comments \\
\hline \multirow{5}{*}{ DIB\&DOX@CS-1 } & G@CS-1 & $\mathrm{C}_{51.9} \mathrm{H}_{50.6} \mathrm{Zn}_{3} \mathrm{l}_{7.3} \mathrm{O}_{6} \mathrm{~N}_{12}$ & 2061.02 & - & - & - & \\
\hline & \multirow[t]{2}{*}{ DOX } & \multirow{2}{*}{$3^{*} \mathrm{C}_{4} \mathrm{O}_{2} \mathrm{H}_{8}$} & \multirow[t]{2}{*}{264.32} & \multirow[t]{2}{*}{12.8} & 22.5 & $\sim 50$ & $\begin{array}{l}\text { DOX on the } \\
\text { surface }\end{array}$ \\
\hline & & & & & 14.3 & $50 \sim 130$ & Lattice DOX \\
\hline & DIB & $0.65 * I_{2} \mathrm{C}_{4} \mathrm{H}_{4}$ & 214.44 & 10.4 & 14.5 & $130 \sim 335$ & Lattice DIB \\
\hline & CS-1 & $\mathrm{C}_{36} \mathrm{Zn}_{3} \mathrm{H}_{24} \mathrm{I}_{6} \mathrm{~N}_{12}$ & 1582.26 & - & - & $335 \sim 559$ & $\begin{array}{l}\text { decompositi } \\
\text { on }\end{array}$ \\
\hline \multirow{5}{*}{$\begin{array}{l}\text { DITFB\&MTS@CS- } \\
1\end{array}$} & G@CS-1 & $\begin{array}{l}\mathrm{C}_{49.8} \mathrm{H}_{34.5} \mathrm{Zn}_{3} \mathrm{I}_{7.6} \mathrm{~N}_{12} \\
\mathrm{~F}_{3.2} \mathrm{Cl}_{9} \mathrm{~S}_{0.75} \mathrm{O}_{1.5}\end{array}$ & 2389.56 & - & - & - & \\
\hline & $\mathrm{CHCl}_{3}$ & $3 * \mathrm{CHCl}_{3}$ & 358.13 & 15.00 & 20.7 & $35 \sim 166$ & $\begin{array}{l}\text { Surface and } \\
\text { lattice } \mathrm{CHCl}_{3}\end{array}$ \\
\hline & MST & $0.75 * \mathrm{C}_{8} \mathrm{H}_{10} \mathrm{SO}_{2}$ & 127.67 & 5.34 & \multirow{2}{*}{25.2} & \multirow{2}{*}{$165^{\sim 320}$} & \multirow{2}{*}{$\begin{array}{l}\text { Lattice } \\
\text { MST@DITFB }\end{array}$} \\
\hline & DITFB & $0.8 * \mathrm{C}_{6} \mathrm{I}_{2} \mathrm{~F}_{4}$ & 321.5 & 13.45 & & & \\
\hline & CS-1 & $\mathrm{C}_{36} \mathrm{Zn}_{3} \mathrm{H}_{24} \mathrm{I}_{6} \mathrm{~N}_{12}$ & 1582.26 & - & - & $320 \sim 559$ & $\begin{array}{l}\text { decompositi } \\
\text { on }\end{array}$ \\
\hline \multirow{4}{*}{ PFIB\&MTS@CS-1 } & $\mathrm{CHCl}_{3}$ & - & - & - & \multirow[b]{2}{*}{26.7} & \multirow[b]{2}{*}{$35 \sim 112$} & \multirow{2}{*}{$\begin{array}{l}\text { Surface } \\
\mathrm{CHCl}_{3} \quad \text { \& } \\
\text { Lattice PFIB }\end{array}$} \\
\hline & PFIB & - & - & - & & & \\
\hline & MST & - & - & - & 7.8 & $112 \sim 325$ & Lattice MST \\
\hline & CS-1 & - & - & - & 48.9 & $350 \sim 587$ & $\begin{array}{l}\text { decompositi } \\
\text { on }\end{array}$ \\
\hline \multirow{4}{*}{ IB\&MTS@CS-1 } & $\mathrm{CHCl}_{3}$ & - & - & - & \multirow[b]{2}{*}{22.6} & \multirow[b]{2}{*}{$35 \sim 115$} & \multirow{2}{*}{$\begin{array}{l}\text { Surface } \\
\mathrm{CHCl}_{3} \quad \text { \& } \\
\text { Lattice IB }\end{array}$} \\
\hline & IB & - & - & - & & & \\
\hline & MST & - & - & - & 9.4 & $115^{\sim 346}$ & Lattice MST \\
\hline & CS-1 & - & - & - & 51.1 & $146 \sim 595$ & $\begin{array}{l}\text { decompositi } \\
\text { on }\end{array}$ \\
\hline
\end{tabular}




\section{CRYSTALLOGRAPHIC ANALYSES}

The data for crystals of DITFB\&MST@CS-1, DIB\&DOX@CS-1, IB\&DOX@CS-1 and PFIB\&DOX@CS-1were collected at $100 \mathrm{~K}$ with a Rigaku XtaLAB AFC12 (RINC): Kappa single CCD using rotating-anode $\mathrm{X}$-ray tube (Mo- $K \alpha, \lambda=0.71073 \AA$ ) radiation. CrysAlisPro ${ }^{2}$ was used for both data collection and processing. The intensities were corrected for absorption using analytical face index absorption correction method $^{3}$ for DITFB\&MST@CS-1, PFIB\&DOX@CS-1 and IB\&DOX@CS-1, and gaussian integration method ${ }^{2}$ for DIB\&DOX@CS-1. The structures were solved by Direct method with $S H E L X T^{4}$ and refined by full-matrix leastsquares methods using the $O L E X 2,{ }^{5}$ which utilizes the SHELXL-2015 module. ${ }^{6}$ All nonhydrogen atoms in the four structures except the iodine in PFIB\&DOX@CS-1 and IB\&DOX@CS-1 were refined with anisotropic thermal parameters.

In DITFB\&MST@CS-1, after assignment of the CS-1 framework, very large residue densities can be observed, which corresponded to the iodine atoms from the DITFB molecules. The occupancies of the iodine were freely refined and then fixed o 0.5 and 0.3 based on the refined values. Then the tetrafluorobenzene group was able to be detected from the difference Fourier map. Due to the highly disorder, free refinement would result in an unreasonable geometry, thus the benzene rings were constrained by "AFIX 66" command. The ADPs were also restrained with "SIMU" and "ISOR" commands. The molecule of CS was also able to be seen from the difference Fourier map. At the same area, some strong residue densities were also observed. They were best accounted by chloroform. The benzene ring in CS was constrained with "AFIX 66 ", and the C-Cl bond lengths of chloroform were restrained with "DFIX 1.78". ADP restraints ("SIMU" and "ISOR") were also applied to the disordered CSF and chloroform molecules. The badly disordered guest/solvent molecules in other places were treated by "SQUEEZE" with PLATON. ${ }^{7}$ Combing the guest/solvent used, and the calculated volume $\left(4 * 216 \AA^{3}\right)$ and electron counts $(4 * 85)$, it was proposed that around 6 disordered chloroform molecules in the unit cell were squeezed out. They were considered in the molecular formula.

In DIB\&DOX@CS-1, the structural refinement strategy used was similar with that for DITFB\&MST@CS-1. In detail, the assignment of iodine atoms was done after the CS-1 framework. The benzene ring was unambiguously seen from the difference Fourier map once the anisotropic model of the heavy atoms were refined. "AFIX 66" was applied for the benzene ring to ensure the geometry. For the two iodine with low occupancy (ca. 0.15), it was not possible to observe the carbon atoms in between.

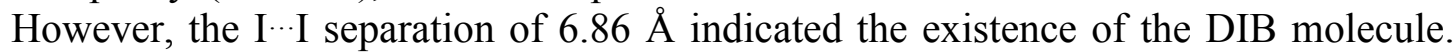
Then, harsh constraints ("AFIX 66") and restraints ("FLAT 0.01", "SADI 0.01", "SIMU", and "ISOR 0.01 0.02") were applied to this low occupancy DIB. Dioxane molecules were clearly observed at three sites, with the occupancies of ca. 1, 0.5 and 0.5 ". Their geometry and anisotropic displacement parameters were restrained with "DFIX 1.45" (for C-O bonds), "DFIX 1.52" (for C-C bonds), "DANG 2.45" (for 1,3$\mathrm{C} \cdots \mathrm{C}$ ), and "ISOR 0.010 .02 " (for C and $\mathrm{O}$ with bad ADP). Due to the high symmetry, the guest molecule in the cavity was heavily disordered. The badly disordered guest/solvent molecules in other places were treated by "SQUEEZE" with PLATON.? Combing the guest/solvent used, and the calculated volume $\left(4 * 351 \AA^{3}\right)$ and electron counts $(4 * 109)$, it was proposed that around twelve 1,4-dioxane molecules in the unit cell were squeezed out. They were considered in the molecular formula.

In PFIB@DOX@CS-1, after assignment of the CS-1 framework, three six-member rings and several strong residual density peaks can be clearly seen. The six-member 
ring were assigned as 1,4-dioxane molecules. The large residual density peaks (larger than 2.0) were assigned as iodine atoms with fixed ADP of 0.15 and free occupancies. The free refinement resulted in the seven iodine atoms with occupancies ranging from 0.09 to 0.29 . The heavy disorder caused the difficulty in observing the pentafluorobenzyl groups. No attempts were made to model the full PFIB molecules due to the low occupancies. Geometry of the 1,4-dioxane molecules were restrained via "DFIX 1.520 .02 " for the C-C bonds and "DFIX 1.450 .02 " for the C-O bonds. The anisotropic displacement parameters were restrained with "ISOR 0.020 .04 " command.

In IB@DOX@CS-1, after assignment of the CS-1 framework, three six-member rings and several strong residual density peaks can be clearly seen. The six-member ring were assigned as 1,4-dioxane molecules. The large residual density peaks (larger than 2.0) were assigned as iodine atoms with fixed ADP of 0.15 and free occupancies. The free refinement resulted in the seven iodine atoms with occupancies ranging from 0.09 to 0.29 . The heavy disorder caused the difficulty in observing the pentafluorobenzyl groups. No attempts were made to model the full PFIB molecules due to the low occupancies. Geometry of the 1,4-dioxane molecules were restrained via "DFIX 1.520 .02 " for the C-C bonds and "DFIX 1.450 .02 " for the C-O bonds. The anisotropic displacement parameters were restrained with "ISOR 0.020 .04 " command.

Crystal data DITFB\&MST@CS-1: $0.10 \times 0.27 \times 0.43 \quad \mathrm{~mm}$, $\mathrm{C}_{49.30} \mathrm{H}_{34} \mathrm{Cl}_{7.50} \mathrm{~F}_{3.20} \mathrm{I}_{7.60} \mathrm{~N}_{12} \mathrm{O}_{1.50} \mathrm{~S}_{0.75} \mathrm{Zn}_{3}, M=2329.75$, monocinlic, space group $C 2 / c, a$ $=35.3505(12) \AA, b=14.6973(3) \AA, c=31.1994(13) \AA, \beta=100.690(4)^{\circ}, V=15928.6(9)$ $\AA^{3}, Z=8, \rho=1.943 \mathrm{~g} \mathrm{~cm}^{-3}, \mu=4.161 \mathrm{~mm}^{-1}, F(000)=8695,46630$ reflections $\left(\theta_{\max }=\right.$ $\left.25.249^{\circ}\right)$ measured $\left(14340\right.$ unique, $R_{\text {int }}=0.0473$, completeness $\left.=99.5 \%\right)$, Final $R$ indices $(I>2 \sigma(I)): R_{I}=0.0943, w R_{2}=0.2431, R$ indices (all data): $R_{I}=0.1097, w R_{2}=$ 0.2537 . $G O F=1.048$ for 933 parameters and 351 restraints, largest diff. peak and hole $3.946 /-1.982 e \AA^{-3}$. CCDC-1895266 contains the supplementary data for this structure.

Crystal data DIB\&Dioxane@CS-1: $0.08 \times 0.20 \times 0.29 \mathrm{~mm}, \mathrm{C}_{52.90} \mathrm{H}_{52.60} \mathrm{I}_{7.30} \mathrm{~N}_{12} \mathrm{O}_{6.50} \mathrm{Zn}_{3}$, $M=2082.95$, monoclinic, space group $C 2 / c, a=34.8220(8) \AA, b=14.7534(2) \AA, c=$

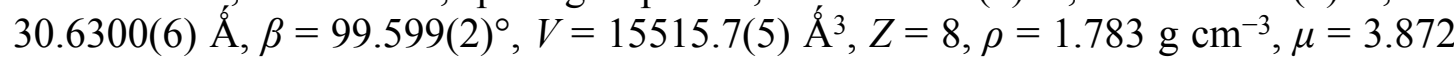
$\mathrm{mm}^{-1}, F(000)=7863,123887$ reflections $\left(\theta_{\max }=25.248^{\circ}\right)$ measured (14057 unique, $R_{\text {int }}=0.0470$, completeness $\left.=100.00 \%\right)$, Final $R$ indices $(I>2 \sigma(I)): R_{I}=0.0918, w R_{2}=$ $0.2560, R$ indices (all data): $R_{I}=0.0997, w R_{2}=0.2634 . G O F=1.117$ for 850 parameters and 311 restraints, largest diff. peak and hole 2.553/-3.898 e $\AA^{-3}$. CCDC-1895267 contains the supplementary data for this structure.

Crystal data PFIB\&DOX@CS-1: $0.10 \times 0.22 \times 0.33 \mathrm{~mm}, \mathrm{C}_{45} \mathrm{H}_{42} \mathrm{I}_{6.68} \mathrm{~N}_{12} \mathrm{O}_{4.50} \mathrm{Zn}_{3}, M=$ 1866.07, monoclinic, space group $C 2 / c, a=34.6753(10) \AA, b=14.7982(4) \AA, c=$ $31.4121(6) \AA ̊ 丿, \beta=101.177(3)^{\circ}, V=15812.8(8) \AA^{3}, Z=8, \rho=1.568 \mathrm{~g} \mathrm{~cm}^{-3}, \mu=3.547$ $\mathrm{mm}^{-1}, F(000)=7006,53287$ reflections $\left(\theta_{\max }=29.277^{\circ}\right)$ measured (18111 unique, $R_{\text {int }}$ $=0.0332$, completeness_full $=99.5 \%$, completeness_max $=83.9 \%)$, Final $R$ indices $(I>$ $2 \sigma(I)): R_{I}=0.0746, w R_{2}=0.2278, R$ indices (all data): $R_{I}=0.1006, w R_{2}=0.2472 . G O F$ $=1.037$ for 766 parameters and 137 restraints, largest diff. peak and hole 1.974/-1.621 $e \AA^{-3}$. CCDC-1915405 contains the supplementary data for this structure.

Crystal data IB\&DOX@CS-1: $0.06 \times 0.49 \times 0.58 \mathrm{~mm}, \mathrm{C}_{42} \mathrm{H}_{36} \mathrm{I}_{6.19} \mathrm{~N}_{12} \mathrm{O}_{3} \mathrm{Zn}_{3}, M=1737.81$, monoclinic, space group $C 2 / c, a=34.635(2) \AA, b=14.7793(4) \AA, c=31.4237(19) \AA$, $\beta=101.567(6)^{\circ}, V=15758.4(14) \AA^{3}, Z=8, \rho=1.465 \mathrm{~g} \mathrm{~cm}^{-3}, \mu=3.362 \mathrm{~mm}^{-1}, F(000)$ $=6510,48996$ reflections $\left(\theta_{\max }=29.171^{\circ}\right)$ measured (17944 unique, $R_{\mathrm{int}}=0.0633$, 
completeness $=99.3 .00 \%)$, Final $R$ indices $(I>2 \sigma(I)): R_{I}=0.0918, w R_{2}=0.2560, R$ indices (all data): $R_{1}=0.1175, w R_{2}=0.3088$. $G O F=1.075$ for 765 parameters and 169 restraints, largest diff. peak and hole 1.910/-1.092e $e \AA^{-3}$. CCDC-1915406 contains the supplementary data for this structure.

Table S2 Comparison of the unit cell parameters of CS-1, DITFB\&MST@CS-1, and DIB\&DOX@CS-1.

\begin{tabular}{|l|l|l|l|}
\hline & CSF-1 $^{1}$ & DITFB\&MST@CS-1 & DIB\&DOX@CS-1 \\
\hline$a(\AA)$ & 34.6555 & $35.3505(12)$ & $34.8220(8)$ \\
\hline$b(\AA)$ & 14.7307 & $14.6973(3)$ & $14.7534(2)$ \\
\hline$c(\AA)$ & 31.0808 & $31.1994(13)$ & $30.6300(6)$ \\
\hline$\beta\left(^{\circ}\right)$ & 101.031 & $100.690(4)^{\circ}$ & $99.599(2)$ \\
\hline$V\left(\AA^{3}\right)$ & 15573.460 & $15928.6(9)$ & $15515.7(5)$ \\
\hline
\end{tabular}

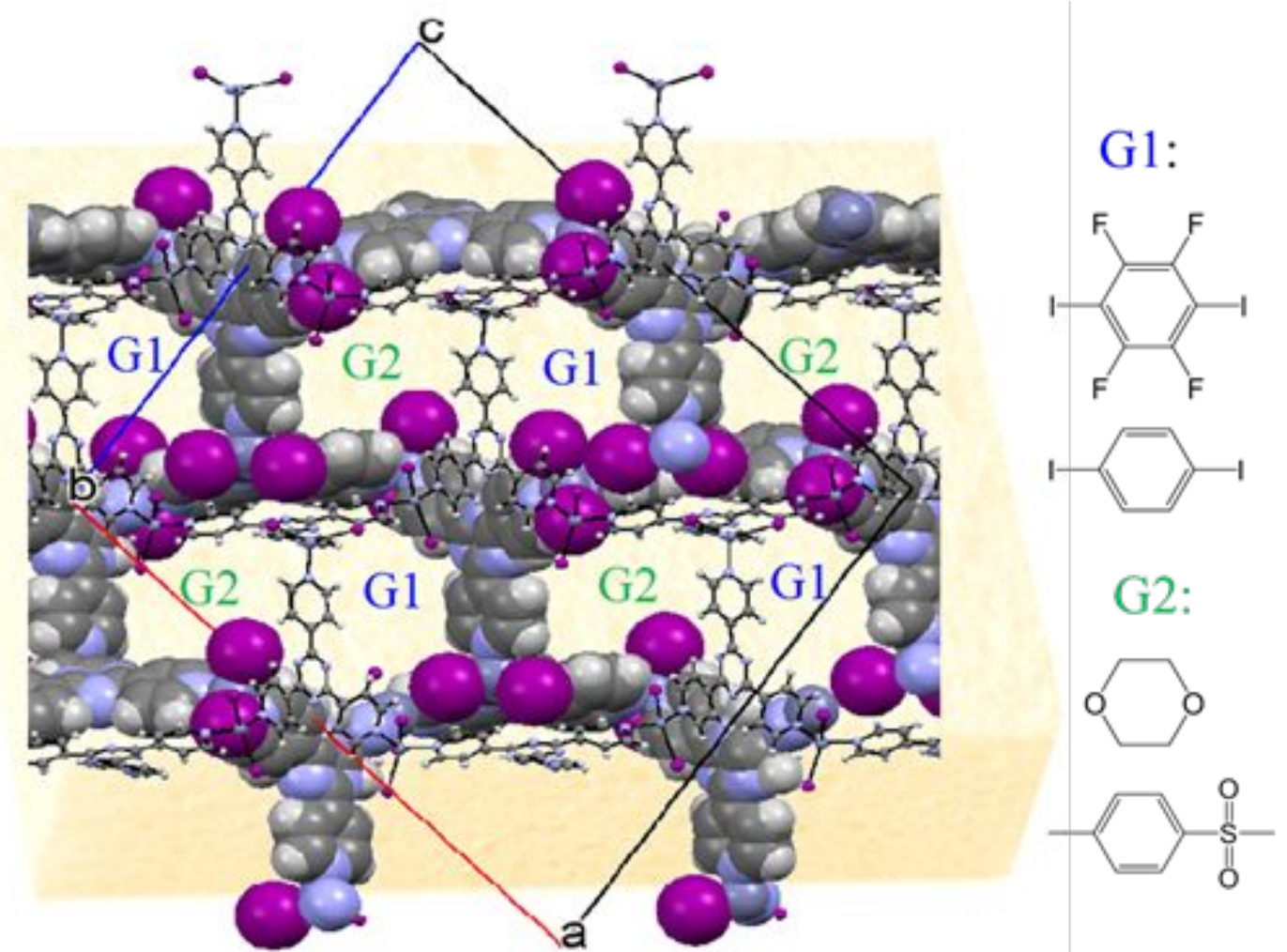

Figure S9. Representation of the two Guests (G1 and G2) in the pores of CS-1. 


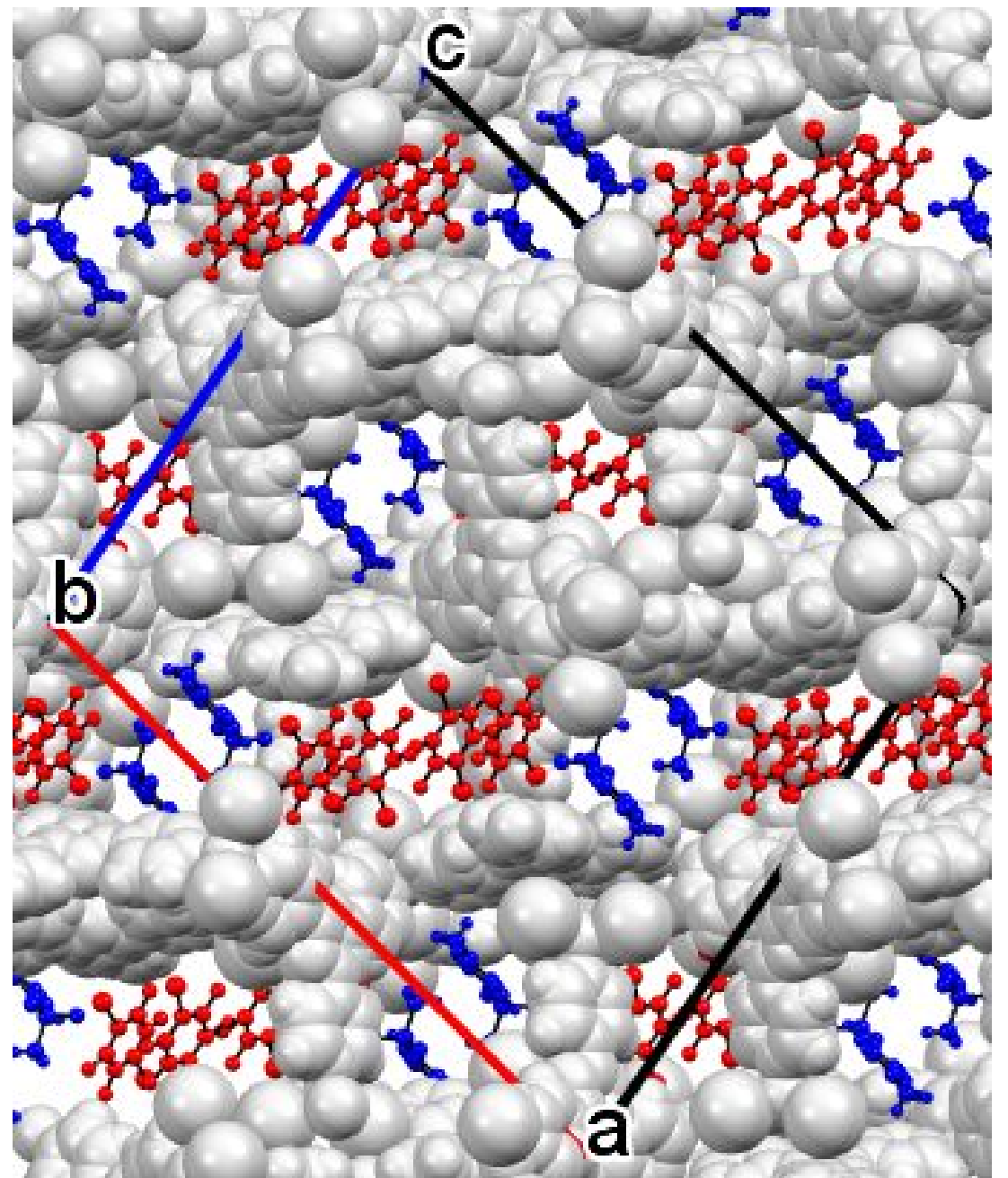

Figure S10. Packing view of the DITFB (in red) and MST (in blue) in the channels of the CS-1 (in CPK mode with light grey color) in DITFB\&MST@CS-1. 


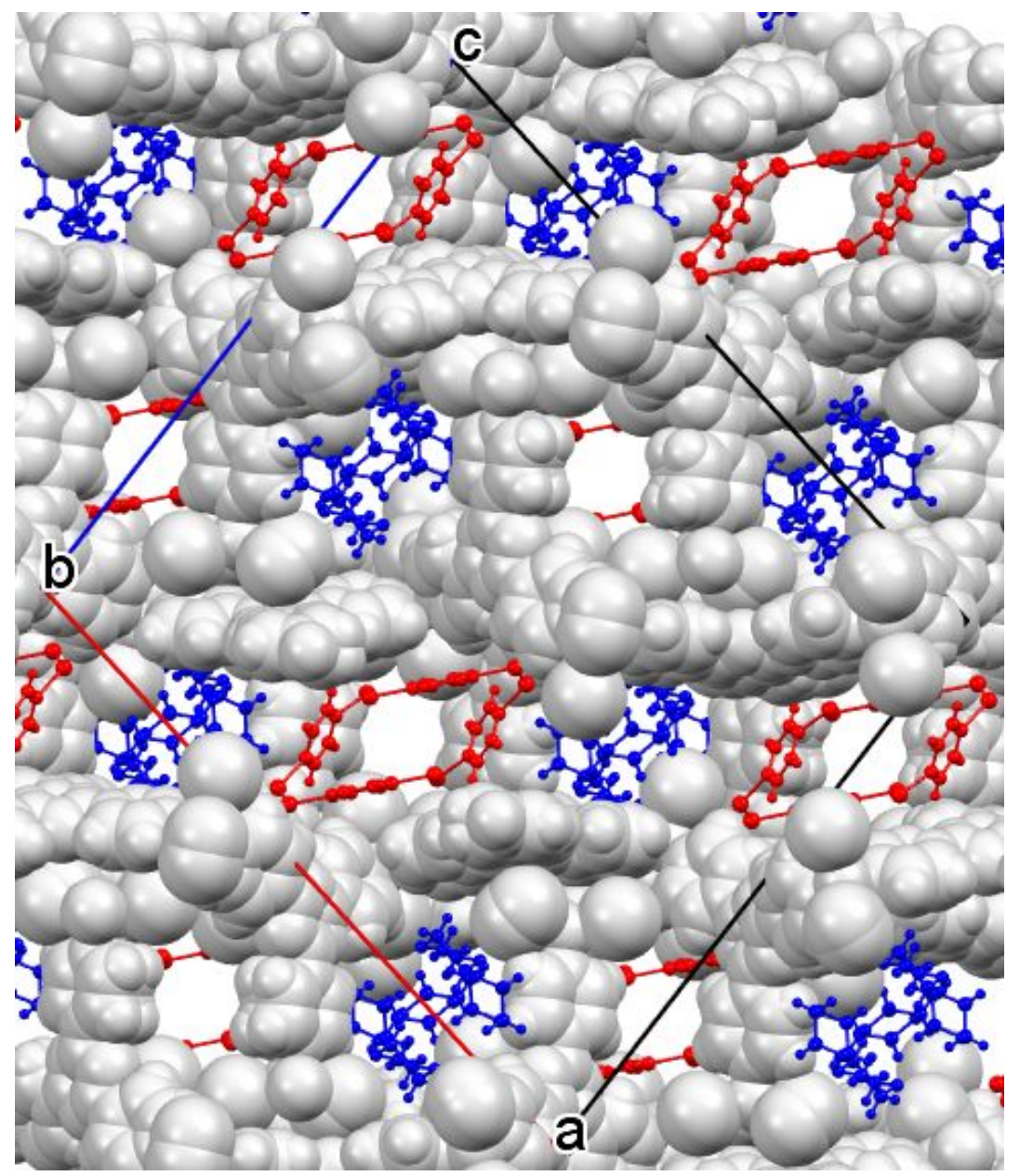

Figure S11. Packing view of the DIB (in red) and DOX (in blue) in the channels of the CS-1 (in CPK mode with light grey color) in DIB\&DOX@CS-1. 


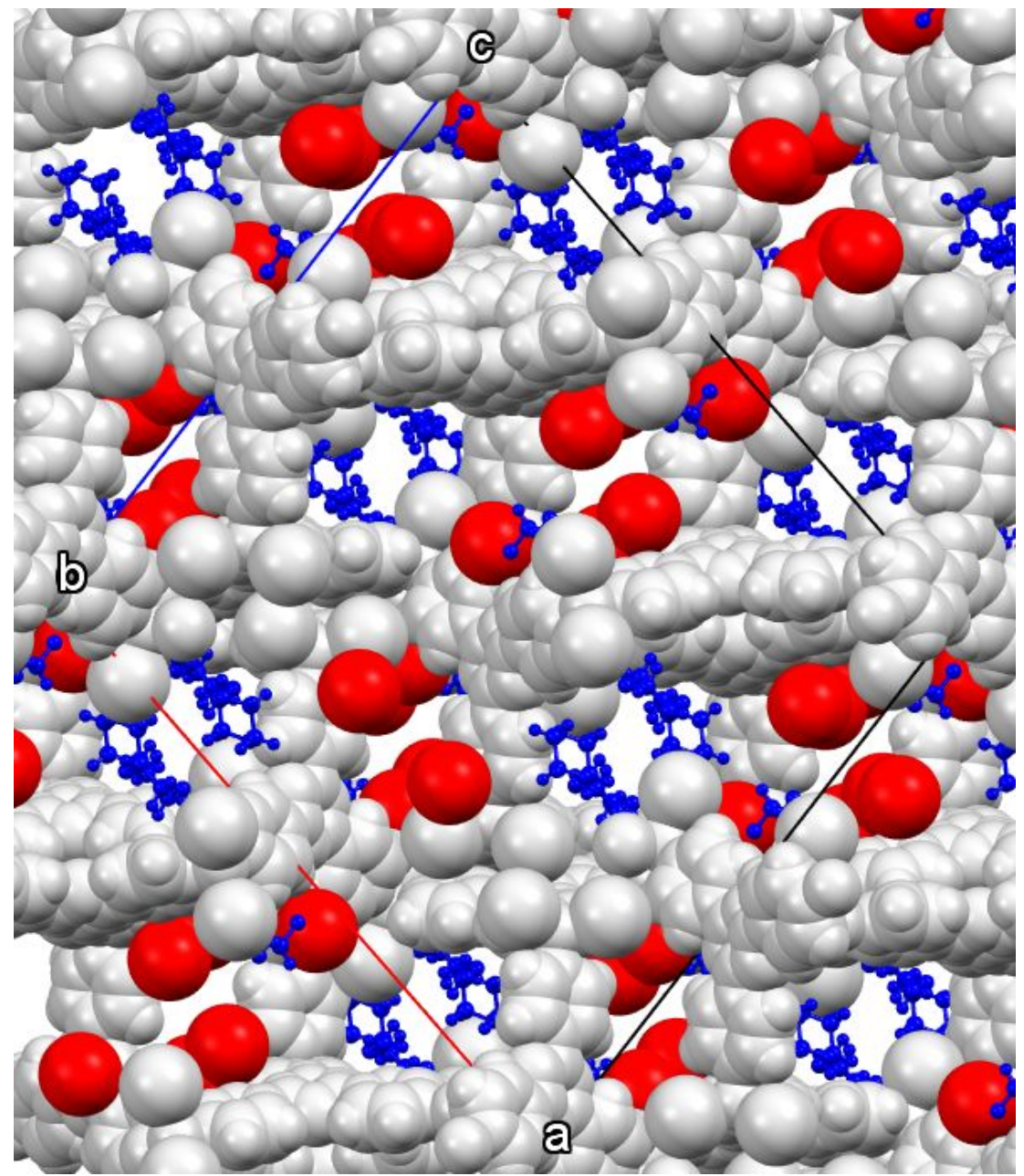

Figure S12. Packing view of the PFIB (only iodine atoms were assigned in red in CPK) and DOX (in blue) in the channels of the CS-1 (in CPK mode with light grey color) in DIB\&DOX@CS-1. 


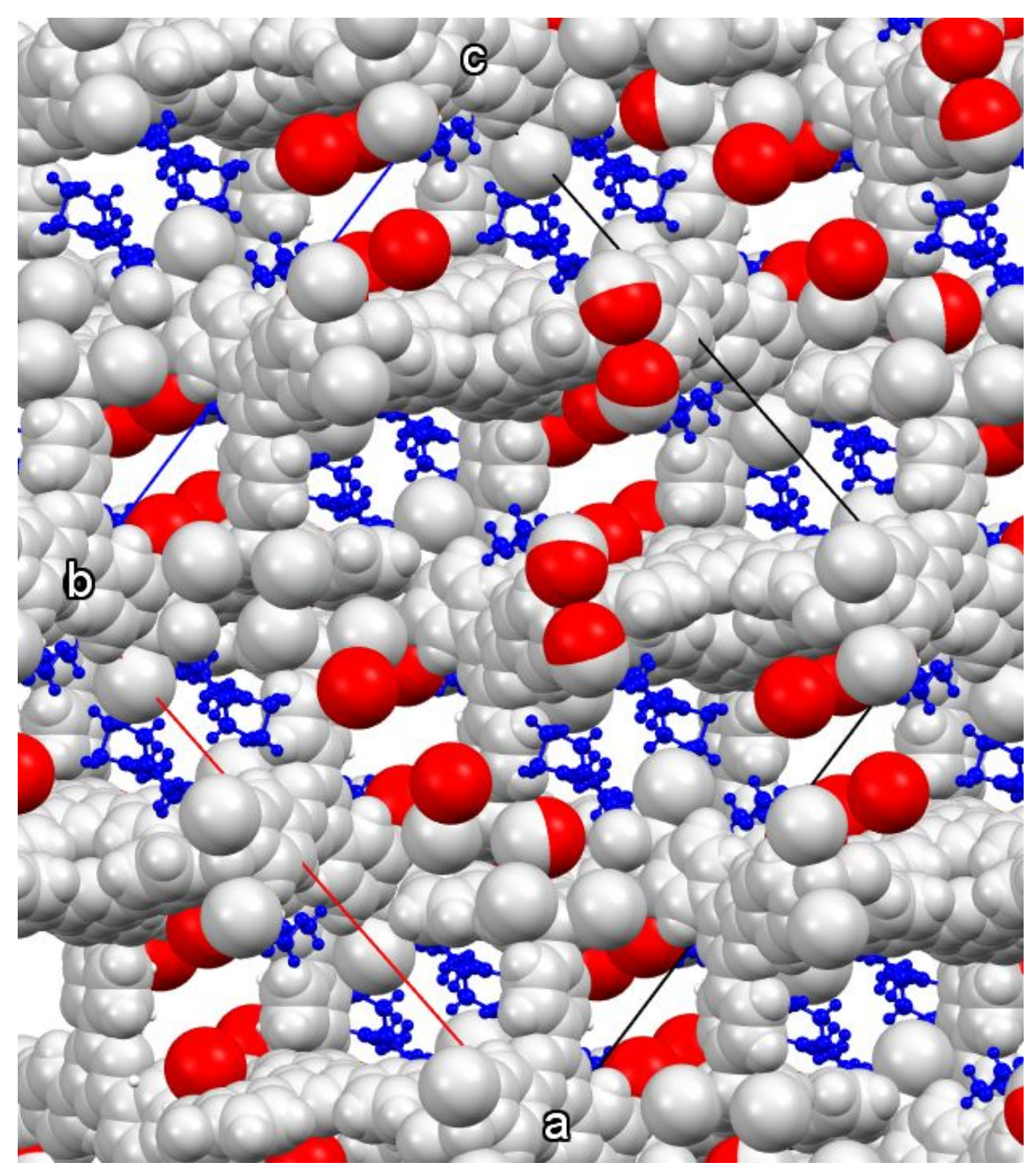

Figure S13. Packing view of the IB (only iodine atoms were assigned in red in CPK) and DOX (in blue) in the channels of the CS-1 (in CPK mode with light grey color) in DIB\&DOX@CS-1. 

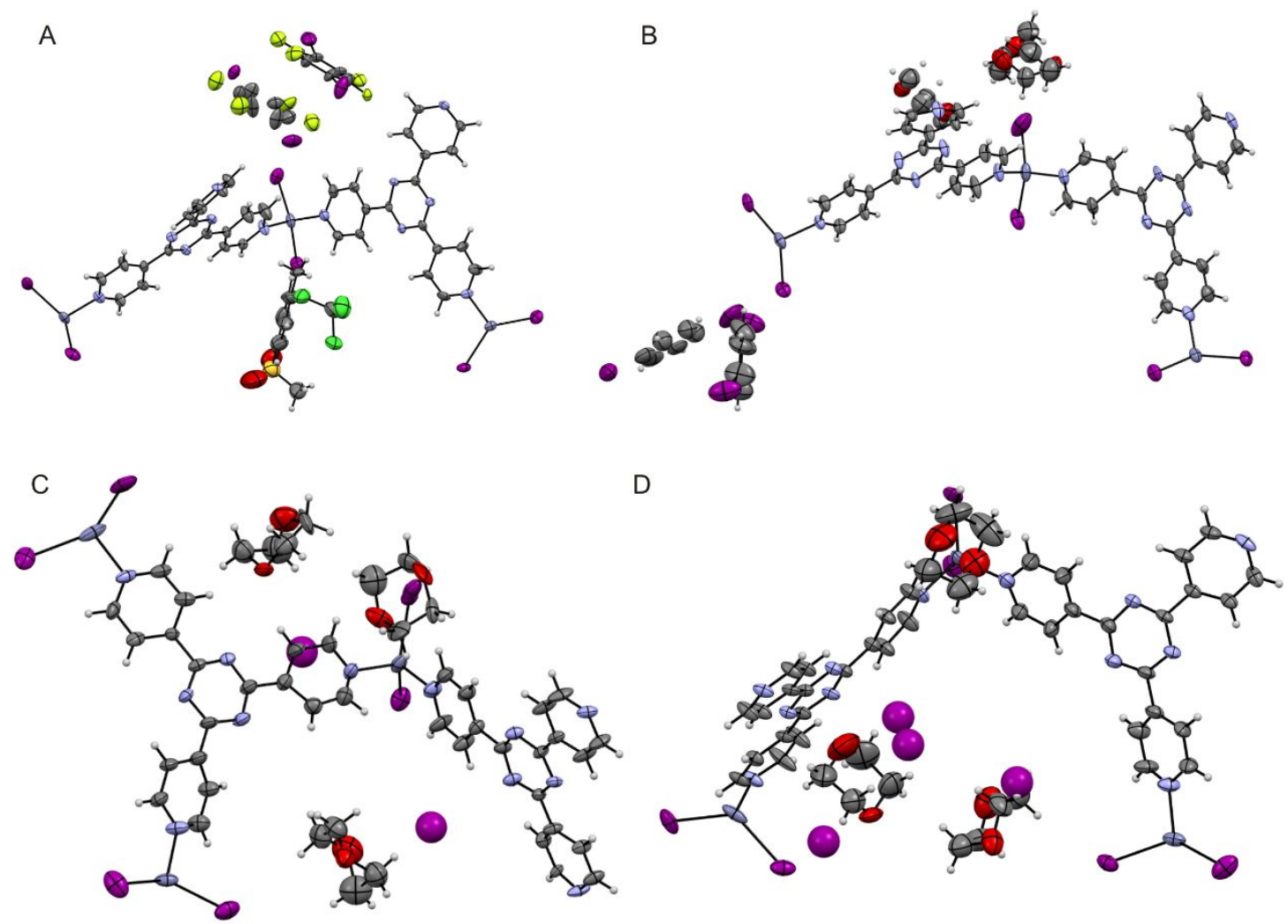

Figure S14. ORTEP plots for the structures of DITFB\&MST@CS-1 (A), DIB\&DOX@CS-1 (B), PFIB\&DOX@CS-1 (C), and IB\&DOX@CS-1 (D). The disorder of the CS-1 frameworks (minor part) and the disordered $\mathrm{CHCl}_{3}$ in DITFB\&MST@CS-1were omitted for clarity. 


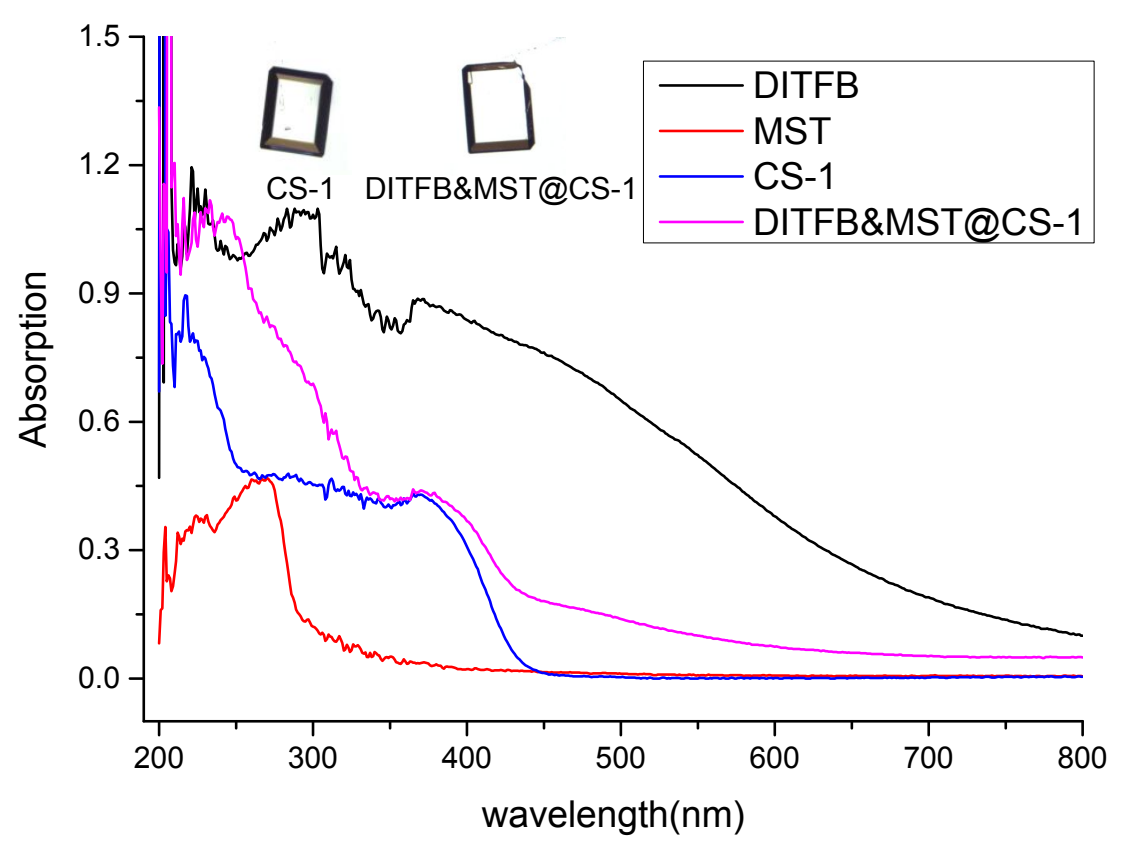

Figure S15. The solid state UV-vis absorption spectra of DITFB, MST, CS-1, and DITFB\&MST@CS-1, as well as the photographs of the crystals before and after guest absorption.

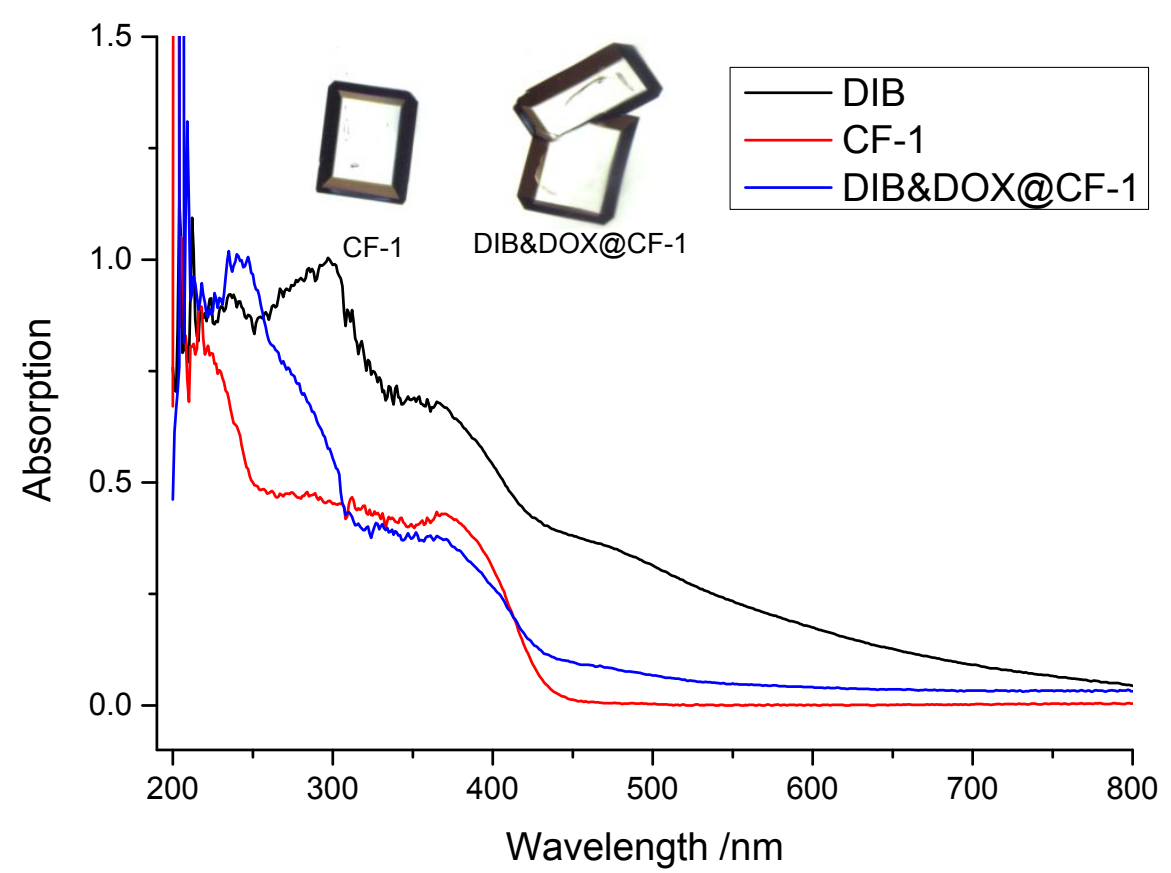

Figure S16. The solid state UV-vis absorption spectra of DIB, CS-1, and DIB\&DOX@CS-1, as well as the photographs of the crystals before and after guest absorption. 


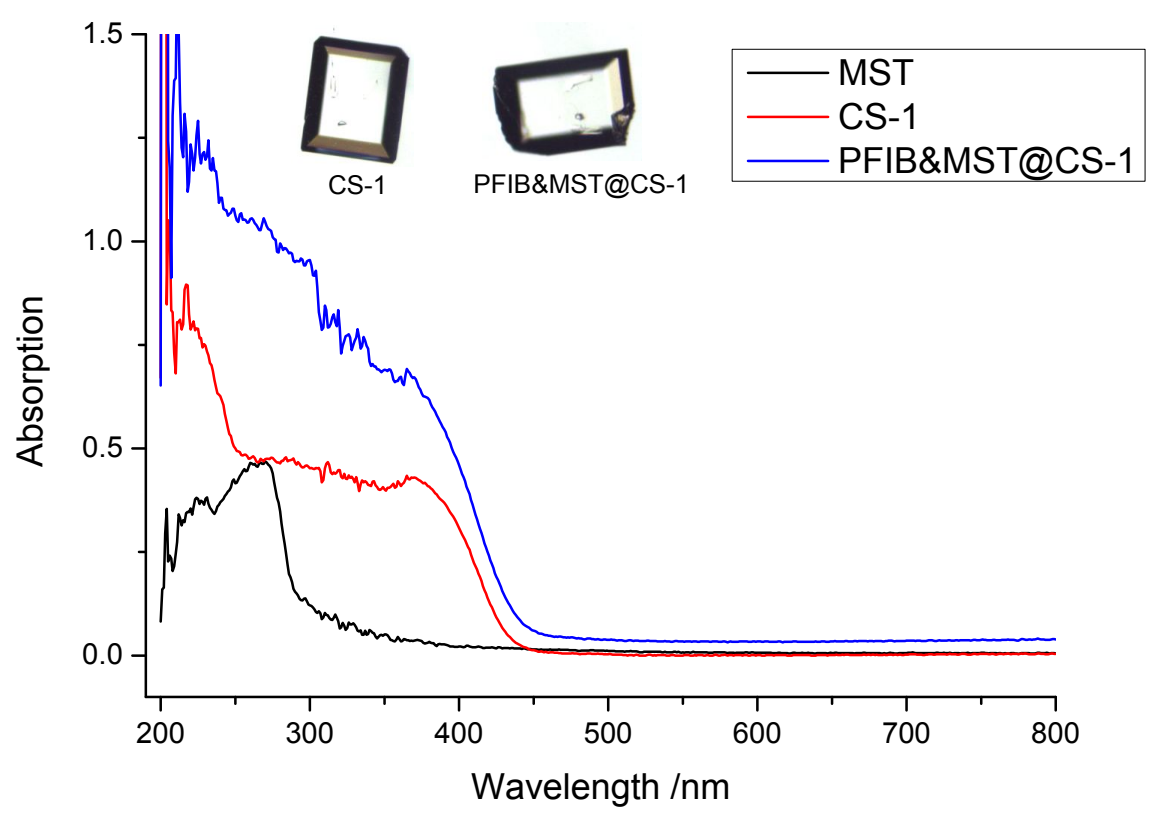

Figure S17. The solid state UV-vis absorption spectra of MST, CS-1, and PFIB\&MST@CS-1, as well as the photographs of the crystals before and after guest absorption.

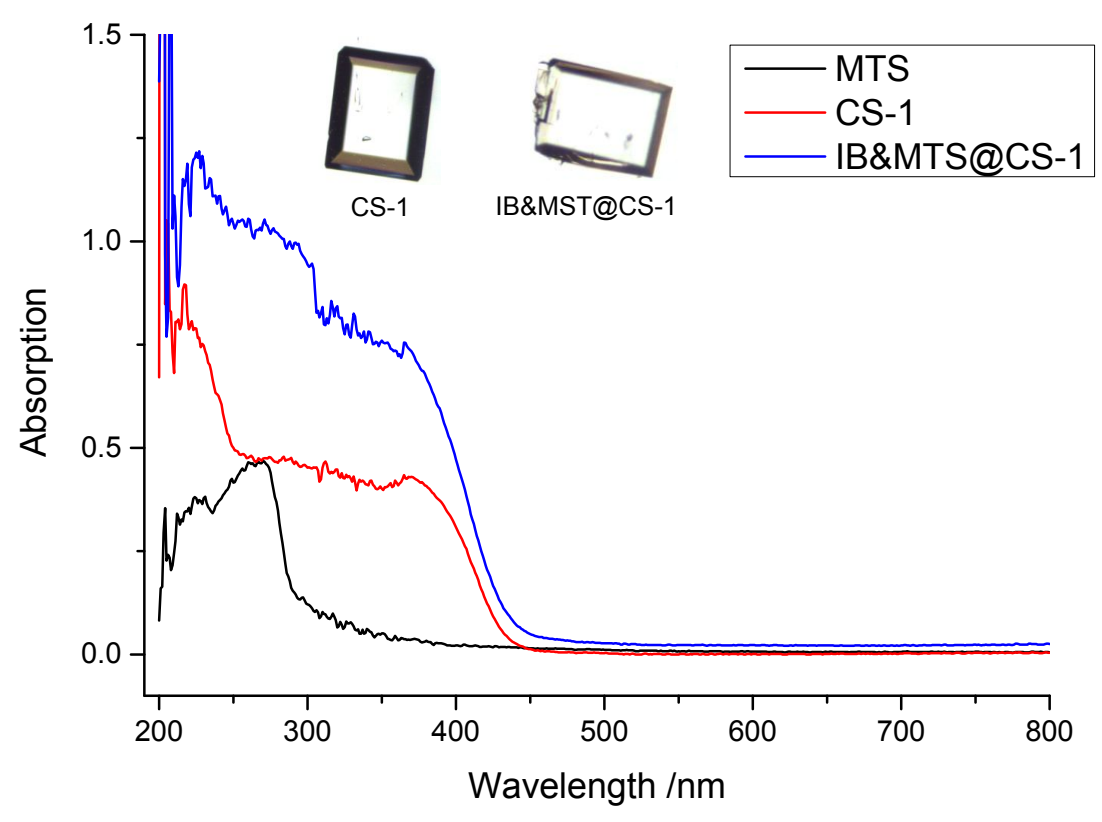

Figure S18. The solid state UV-vis absorption spectra of MST, CS-1, and IB\&MST@CS-1, as well as the photographs of the crystals before and after guest absorption. 


\section{REFERENCES}

1. Ramadhar, T. R.; Zheng, S. L.; Chen, Y. S. and Clardy, J. The crystalline sponge method: a solvent-based strategy to facilitate noncovalent ordered trapping of solid and liquid organic compounds. CrystEngComm 2017, 19, 4528-4534.

2 CrysAlisPro 2018, Rigaku Oxford Diffraction. Version 1.171.39.46e.

3. Clark, R. C.; Reid, J. S. The Analytical Calculation of Absorption in Multifaceted Crystals. Acta Cryst. A 1995, 51, 887-897.

4. Sheldrick, G. M. SHELXT - Integrated space-group and crystal-structure determination. Acta Cryst. 2015, A71, 3-8.

5. O. V. Dolomanov, O. V.; Bourhis, L. J.; Gildea, R. J.; Howard, J. A. K.; Puschmann, H. OLEX2: a complete structure solution, refinement and analysis program. J. Appl. Cryst. 2009, 42, 339-341.

6. Sheldrick, G. M. Crystal structure refinement with SHELXL. Acta Cryst. 2015, C71, 3-8.

7. Spek, A. L. Structure validation in chemical crystallography. Acta Cryst. 2009, D65, 148-155. 